\section{No cure for headaches in the pharmaceutical industry}

PUBlic disquiet about drug safety is unlikely to be lessened by last week's developments in Britain. First Zomax, a widely prescribed painkiller, was withdrawn from sale following five deaths in the United States which appear to be linked with the drug. Later, a report published by the Consumers' Association criticized the safety record of Distalgesic, by far the most commonly prescribed analgesic of its type in Britain. So soon after the publication of the Greenfield Report, which encourages more generic prescribing, these events could hardly have come at a worse time for the pharmaceutical industry.

Zomax (zomepirac sodium), manufactured by a subsidiary of Johnson and Johnson, is a non-steroidal anti-inflammatory drug introduced in Britain in 1980. Since then, an estimated 20 million people worldwide have taken the drug. Its distributors in the United States, McNeil Pharmaceuticals, first became aware of anaphylactoid shock reactions in some patients last year. Two patients in the United States known to be hypersensitive to

\section{Super-Sara obituary}

\section{Brussels}

THE Super-Sara reactor safety project at the European Community's joint research centre at Ispra in Italy was quietly abandoned last Thursday at the meeting of the Ten's research ministers. Italian objections were overcome by assurances that spending levels would be maintained and that every effort would be made to site the next big fusion machine at Ispra.

The debate on the European Commission's proposals for research projects to take the place of Super-Sara revolved around a tritium-handling laboratory, which in the non-military field is lacking in the European fusion effort; an earthquake simulation machine intended to find out how well large nuclear and non-nuclear installations would stand up to catastrophic impacts, and feasibility studies on either Ignitor, one of the alternative fusion machines to the tokamak, or NET (the Next European Torus).

More discussions will take place throughout the year, but one thing is certain: the Commission has a budget of $\mathbf{7 0 0}$ million European Currency Units (ECU) ( $£ 1,500$ million) to spend on research between 1984 and 1987 and 2,260 people to occupy. The council decided to allocate 20 million ECU partially to decommission the Essor experimental reactor, half of what the Commission had originally estimated was needed, which suggests that further uses will be found for it. Jasper Becker aspirin died, as a result of which prescribing advice was altered to emphasize the unsuitability of the drug for patients with aspirin or other anti-inflammatory induced allergy. Another three deaths this year, still under investigation, prompted McNeil voluntarily to withdraw Zomax from the US market while further labelling changes are considered.

The distributors of Zomax in Britain, Ortho-Cilag Pharmaceuticals Ltd, followed suit after consultations with the Committee on Safety of Medicines. Dr Wendy Jefferson, medical director of OrthoCilag, points out that at least until last month, no deaths associated with Zomax are known to have occurred in Europe.

Distalgesic is another matter. The Consumers' Association report, published in its Drugs and Therapeutics Bulletin, asserts that Distalgesic is the drug most commonly associated with suicidal and accidental drug death in Britain even though it is a prescription-only medicine and so less widely available than other potentially fatal drugs. The report pins the blame on a component of Distalgesic called dextropropoxyphene (DP), an opioid analgesic. Some doctors feel that the efficacy of Distalgesic owes something to a psychotropic effect of DP, and its use is banned in some hospitals. The Consumers' Association report concludes that there is insufficient evidence that the combination of DP and paracetamol contained in Distalgesic is more effective than paracetamol alone, and that "uncritical" use of the drug seems "pointless and hazardous". DP overdose causes rapid death through respiratory failure, and the suggestion appears to be that the safety margin between the recommended therapeutic dose and a lethal dose is too narrow.

The coroner of the city of Birmingham, Dr Richard Whittington, estimates that up to 500 deaths a year may be caused in Britain by Distalgesic, especially when it is taken with alcohol.

Distalgesic is manufactured by Dista Products Ltd. Dr Wilson Totten, medical adviser for the company, denies that the safety margin of Distalgesic is lower than that of other centrally-acting analgesics, and refutes suggestions that mild dependence on Distalgesic may be widespread.

Dr Totten claims the evidence presented in the Consumers' Association report is incomplete, and criticizes its authors for distributing copies to the lay press at the same time as submitting it to the regulatory authorities. The Committee on Safety of Medicines has now decided to "consider whether there is any new evidence" bearing on the safety of Distalgesic.

Tim Beardsley
Belgian archaeology

Neanderthals hit

Brussels

THE grave financial problems of the University of Liège are threatening excavations at a site which promises to reveal new evidence about the evolution of man in Europe. The site, at Belle Roche some 30 $\mathrm{km}$ south of Liège, was discovered three years go by a quarryman who noticed some fossil fragments in a band of lime deposits. Intense excitement was aroused last year, however, when a team from the University of Liège discovered stone tools which may have been made around 500,000 years ago

Dr Jean-Marie Cordy, a lecturer in palaeontology at the university who has taken charge of the project, thinks that the discovery of the tools indicates a strong

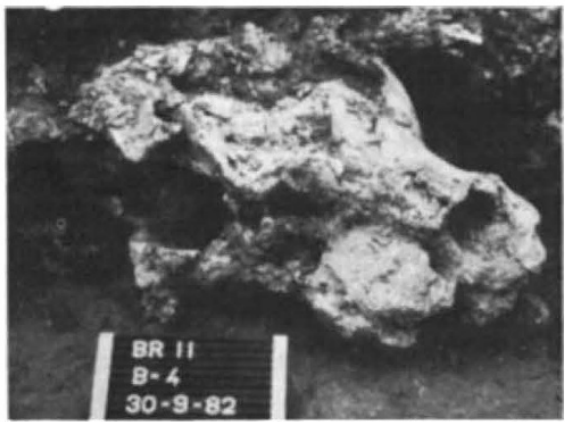

The well preserved cranium of a deninger bear from Belle Roche

possibility that skeletons of preNeanderthal man will be discovered in the next few years. Many plant and animal remains from the middle Pleistocene period have already been identified, including the well-preserved craniums of a deninger bear and a European jaguar. Belle Roche is expected to become one of the key sites for tracing the origins of European man in the period stretching from the appearance of Homo erectus 1.5 million years ago to the arrival of modern man (Homo sapiens sapiens) less than 50,000 years ago.

Unfortunately, the financing of such research is poorly organized in Belgium, and the company that owns the Belle Roche quarry cannot much longer postpone mining the face where the relevant limestone is being excavated.

The university has been able to find the BF $400,000(£ 5,200)$ that the excavation has so far cost, but is now in such dire financial straits that no more money will be forthcoming. Future excavation would require $\mathrm{BF} 2$ million a year. The most pressing need is for a permanent staff of researchers. The dozen or so workers engaged on the actual digging are mostly redundant steelworkers whom the state partly pays to undertake socially desirable work.

For 1983, the financial problems, apart from paying staff, have now been solved thanks to the timely intervention of the Fonds National de la Recherche Scientifique (National Science Research Fund), but the research cannot be managed on a hand to mouth basis.

Jasper Becker 